Diário de Viagens: compartilhando aventuras pelo registro da memória

Revista Ensaios, vol. 15, jul-dez de 2019.

\title{
Diário de Viagens: compartilhando aventuras pelo registro da memória
}

\author{
Luciano Victor Barros Maluly ${ }^{1}$ \\ Clarissa Maria Rosa Gagliardi ${ }^{2}$ \\ Karina Toledo Solha ${ }^{3}$
}

\begin{abstract}
Resumo: Este ensaio aborda o Diário de Viagens como uma possibilidade de compartilhamento das experiências vivenciadas por jornalistas, turismólogos, estudiosos e demais viajantes. Por meio de uma linguagem simples e objetiva, apresenta-se o planejamento para a montagem do Diário de Viagens, desde a captação de informações, passando pela escrita até a publicação, especialmente pelas mídias digitais. Situações passíveis de registro, transformações na forma e no conteúdo registrado nos diários de viagem em diferentes momentos históricos, bem como a quem este tipo de escrita pode interessar, também são aspectos abordados. Um dos objetivos deste ensaio é demonstrar que o registro da memória se estabelece pelos processos de comunicação.
\end{abstract}

Palavras-chave: Diário de Viagens. Jornalismo Especializado. Turismo.

\section{Travel Journal - sharing adventures by memory record}

Abstract: This essay approaches the Travel Journal as a possibility to share experiences lived by journalists, tourism experts, scholars and other travelers. Through simple and objective language, we present the planning for the creation of a travel journal, from the collection of information, through writing to publishing, specially in digital media. Possible registry situations, changes in form and content of registrations on travel journals in different historical moments as well as to whom this kind of writing may interest are approached topics. One of the objectives of this essay is to demonstrate that the recording of memory is established by the communication processes.

Keywords: Travel Journal. Specialized Journalism. Tourism.

\footnotetext{
1 Doutor em Ciências da Comunicação e professor do curso de Jornalismo, ambos na Escola de Comunicações e Artes da Universidade de São Paulo. Brasil, São Paulo, São Paulo. lumaluly@usp.br.

${ }^{2}$ Doutora em Sociologia pela Pontifícia Universidade Católica de São Paulo e professora do Curso de Turismo na Escola de Comunicações e Artes da Universidade de São Paulo. Brasil, São Paulo, São Paulo. clarissamrg@usp.br.

3 Doutora em Ciências da Comunicação e professora do Curso de Turismo, ambos na Escola de Comunicações e Artes da Universidade de São Paulo. Brasil, São Paulo, São Paulo. kasolha@usp.br.
} 
Diário de Viagens: compartilhando aventuras pelo registro da memória

Revista Ensaios, vol. 15, jul-dez de 2019.

São inesgotáveis as histórias contadas por viajantes. Situações dramáticas ou engraçadas fazem parte do repertório daqueles que se deparam com lugares antes desconhecidos. Desta forma, surgem relatos repletos de novidades e informações para quem deseja fazer o mesmo caminho.

Os turistas são os que mais representam esse grupo. São curiosos em busca de aventuras. Querem conhecer o diferente e o inusitado. Assim, descobrem lugares e pessoas.

O outro grupo é composto pelos conquistadores. São aqueles que viajam em busca de oportunidades, como os que estão a trabalho ou conquistando novos horizontes. Da mesma forma que os colonizadores, têm a descoberta como objetivo ou mesmo como uma obrigação.

E o próximo grupo, talvez o maior deles, é composto pelos visitantes. São aqueles sujeitos que precisam estar temporariamente em um local, independentemente do desejo. Os objetivos são familiares (desde uma simples visita ou mesmo para rituais como o nascimento, o casamento, o velório etc.), de habitat (conhecer ou pesquisar os futuros locais de estudo, trabalho ou mesmo moradia) ou de passagem (um passeio ou parada), entre outros.

O último grupo é formado pelos profissionais do jornalismo e do turismo. Enquanto o jornalista busca as notícias em torno dessas situações, o turismólogo, quando na situação de planejador/consultor, serve mais como um mediador entre a comunidade, os empresários (trade) e a esfera pública, de modo a construir um plano que reflita os anseios coletivos e que os oriente no planejamento turístico do lugar.

Este ensaio revela como é possível aproximar a linguagem jornalística dos viajantes, sendo esse trabalho destinado para quem gosta de escrever e deseja contar as suas experiências e, ao mesmo tempo, diminuir os problemas encontrados nessas viagens. A intenção é a de demonstrar como o Diário de Viagens é útil para registrar certas passagens, assim como para facilitar o caminho dos próximos viajantes. 
Diário de Viagens: compartilhando aventuras pelo registro da memória

Revista Ensaios, vol. 15, jul-dez de 2019.

\section{1) Para entender o Diário de Viagens:}

Os Diários de Viagens são famosos e foram fundamentais, por exemplo, para compreender as dinâmicas de viagens nos séculos XVIII, XIX e XX. Hoje são pouco comentados e mesmo pouco utilizados naquele formato em que as pessoas descreviam e refletiam suas experiências de viagem. Se considerarmos, por exemplo, a obra Viagem à Itália 1786-1788 (1999) de Goethe, composta de cartas e diários de sua viagem empreendida no século XVIII ao solo clássico, encontramos uma descrição minuciosa e de grande sensibilidade a respeito dos lugares por onde passou, como de suas visitas a Roma e Nápoles. Goethe permite ao leitor perceber como era a infraestrutura de hospedagem, alimentação e compreender por que certos locais passam a tornam-se célebres e, assim, gradualmente, vão sendo cristalizados em circuitos culturais a partir do Grand Tour.

Esse tipo de obra ajuda, com o tempo, a qualificar pontos de referência como atrativos culturais, na medida em que, posteriormente, serão paradas obrigatórias em qualquer viagem cultural à Europa a partir das viagens da burguesia e até hoje. Quem deixaria de visitar o Coliseu em uma viagem a Roma?

Contudo, a lógica de registrar e compartilhar as experiências de viagens permanece, mas no formato em que a superficialidade, o imediato e o consumo de experiência imperam. Não se observam as pessoas disponíveis parar refletir sobre isso, porque, neste momento, estão apenas interessadas em consumir viagens. Assim, todo o conteúdo gerado tem sempre um sentido prático, de apoio, de suporte e visibilidade das experiências. E, nesse universo da rapidez e do consumo, a reflexão e o entendimento de toda essa diversidade de realidades do mundo parecem ter pouca importância. Todavia, há indícios de que esse processo se modifique, pois existe a perspectiva de contramovimentos.

Os turistas conscientes, o ecoturismo, as noções de consumo consciente têm formado um outro tipo de grupo de viajantes. Na verdade, um diferenciado grupo de consumidores que refletem sobre seu consumo em todos os campos, inclusive no campo do lazer, do entretenimento e do turismo. E isso também não é tão recente. Se 
Diário de Viagens: compartilhando aventuras pelo registro da memória

Revista Ensaios, vol. 15, jul-dez de 2019.

recuperarmos as discussões sobre ecodesenvolvimento, que gestou a ideia de ecoturismo, desde os anos 1990, pode-se dizer que essa ideia de turismo consciente se fortalece e, assim, produz diferentes experiências de viagem nas quais o consumo e a rapidez não são centrais.

De todo modo, registros escritos sobre viagens sempre estiveram presentes nas histórias das viagens e, posteriormente, do turismo e, portanto, representam documentos importantes ao público, especialmente jornalistas, turismólogos e estudiosos interessados em compreender as transformações deste fenômeno.

\section{2) Escrevendo durante a sua viagem:}

Cada dia é uma novidade e, como se está em trânsito, são muitas as informações a serem guardadas. Por isso, muitas pessoas utilizam aparelhos com capacidade para registrar fotos, áudios e vídeos. Transformar esses dados em texto demanda tempo e não é uma tarefa nada fácil. Permite-se captar detalhes por meio desses dispositivos para, se necessário, reutilizá-los como fontes no futuro. Deixe o aparelho ligado para gravações em audiovisual que ache importantes. Não tenha vergonha e converse com as pessoas, sem compromisso. O que não se pode é perder o momento, inclusive os mais cômicos e dramáticos.

A memória é o principal componente da sua história. Recorde e recorte os detalhes que fizeram parte dessa trajetória. Comece a contar as suas aventuras, seja de maneira oral ou escrita.

$\mathrm{O}$ fato de estar vivendo aquele momento é fundamental e, por isso, tente se desvincular de clichês e estereótipos em alguns trechos do texto. Desta forma, procure contar a sua história e não apenas reproduzir as informações que pesquisou e foram importantes na preparação da viagem.

Inicie seu relato contando como foi a arrumação das malas e dos documentos, além de revelar as fontes de sua pesquisa. Detalhe os pontos positivos e negativos dessa 
Diário de Viagens: compartilhando aventuras pelo registro da memória Revista Ensaios, vol. 15, jul-dez de 2019.

etapa. Depois comece a destacar os detalhes que antecederam a chegada ao local de destino.

Desde a saída de casa, revele as principais características relacionadas ao transporte (o meio e o custo), à alimentação (o que levou ou foi oferecido), à documentação (tipo e retirada), ao local de espera/pontos de embarque (aeroportos, rodoviárias, ferroviárias, portos e outros), à alfândega ou imigração (no caso do exterior), ao free shopping (compras no exterior), ao embarque (se foi tranquilo ou ocorreu algum problema), ao meio de transporte (tipo e conforto), ao entretenimento (particular e o disponibilizado), ao deslocamento (tempo e dificuldades, caso ocorram), desembarque (condições físicas do grupo e das bagagens) e ao transporte local (meio e custo) até a chegada à hospedagem (check-in, check-out e recepção).

Esse último item é fundamental em seu Diário de Viagens, pois revelará a qualidade da acomodação escolhida, assim como o relato sobre as condições das empresas de transporte. O mesmo relato descrito poderá ser reproduzido na sua avaliação desse local. Utilize os mesmos critérios de avaliação disponibilizados pelos espaços de busca online para reserva de acomodações, passagens e pacotes.

Observe a qualidade dos serviços, como a cordialidade dos funcionários, condições de higiene, conforto da habitação, condições de pagamento, serviços extras até verificar se o estabelecimento cumpriu o contrato, ou seja, se valeu o custobenefício. Use os mesmos critérios para avaliar os serviços dos restaurantes, bancos, casas de câmbio, lojas e outros serviços. Assim, poderá auxiliar os futuros viajantes a escolher os melhores serviços, assim como contribuirá para que os estabelecimentos melhorem o atendimento e os produtos oferecidos ao público.

\section{3) Como captar as informações para o seu Diário de Viagens:}

O planejamento do Diário de Viagens começa com a confirmação do(s) locais de destino, sendo essa a primeira e principal informação para montar o seu diário e o 
Diário de Viagens: compartilhando aventuras pelo registro da memória

Revista Ensaios, vol. 15, jul-dez de 2019.

seu passeio. Depois dessa decisão, é só dar o primeiro click e começar a visitar os sítios pela Internet ou através de materiais especializados, brochuras, revistas, livros ou guias.

O custo é a principal preocupação para maioria das pessoas, sendo o transporte e a hospedagem os itens iniciais a serem pesquisados. Por conta disso, guarde essas informações para, se necessário, compor o texto do seu Diário. De cara, o viajante, geralmente, procura as companhias (aéreas, terrestres ou marítimas) e escolhe a melhor opção. Depois, compara os benefícios, como preço, segurança, tempo de viagem e acomodação. Observe ainda os demais serviços disponibilizados, como alimentação, bagagens, marcação de assentos, entretenimento, auxílio às pessoas com necessidades especiais (idosos, pessoas com deficiência e outros) etc. Algumas situações são novas, como o fato de muitas empresas, principalmente as companhias aéreas, cobrarem por quase todos os serviços, gerando um custo enorme além das passagens e da taxa de embarque.

O próximo passo para a captação de informações refere-se à procura das acomodações disponíveis nos locais aonde irá se instalar. Existem diferentes opções nos sites de busca, como hotéis, pensões, hospedarias, hostels, albergues, camping, propriedades urbanas, como casas e apartamentos, e rurais (chácaras, ranchos, sítios, fazendas etc.) particulares e até públicas. Em alguns casos, o aluguel do espaço é exclusivo ou pode ser compartilhado com outras pessoas. Da mesma forma que as passagens, o viajante compara os benefícios, com alguns detalhes a mais, como a localidade e as acomodações, inclusive com os itens de cama, mesa ou banho, fatores que precisam ser observados com atenção. Neste item, as opiniões e avaliações disponibilizadas na internet, especialmente as OTAs (Online Travel Agencies) são importantes elementos nesses dois primeiros passos, justamente para verificar a qualidade desses serviços.

A etapa seguinte para a captação de informações é mais prazerosa, porque será composta pela seleção dos trajetos ou passeios que deseja ou precisa fazer. É a maneira de descobrir novos e já conhecidos pontos de visitação ou passagem, assim como de encurtar os caminhos em certos casos. Sempre é importante ler com atenção os relatos 
Diário de Viagens: compartilhando aventuras pelo registro da memória

Revista Ensaios, vol. 15, jul-dez de 2019.

dos viajantes, em sites ou blogs, assim como em guias impressos e cadernos de viagens já conhecidos.

Caso tenha muita dificuldade e necessite de alguns esclarecimentos, torna-se essencial a ajuda dos amigos que já fizeram esses trajetos, dos agentes de viagens, dos contatos gerados na busca de transporte ou hospedagem etc. Converse com as pessoas que já visitaram o mesmo destino de seu interesse. Se entusiasme com os detalhes, sejam eles positivos, sejam negativos. E principalmente anote tudo e peça para que a pessoa envie detalhes pelas mídias sociais. Não tenha vergonha de pedir ajuda durante a construção do seu roteiro.

A última fase é atribuída aos detalhes, como a compra do seguro-saúde, no caso de visita ao exterior; deslocamento (a pé, de táxi, van, carro, bicicleta, trem, ônibus, metrô, entre outros), por meio de aplicativos ou pontos de partida e chegada; contatos locais, desde pessoas até instituições; tipos e quantidade de vestuário e outros utensílios pessoais, para não ficar carregando malas e outros excessos; restaurantes, lojas, supermercados, bancos, guias, casas de câmbio (verificar o câmbio) e de apoio (ponto de informações turísticas), entre outras questões que facilitarão a sua viagem e aumentarão o tempo para aproveitar os locais de visitação e escrever o seu diário.

Uma observação essencial durante a sua viagem e que será um diferencial no seu texto é a interação com a cultura, a economia, a política, a história, a geografia, o idioma, entre os principais aspectos da localidade a ser conhecida. Seja respeitoso com a tradição e mesmo com o cotidiano desses cidadãos. Muitas vezes, existem conflitos, discussões e acordos em trâmite. Seja sensato com a situação para evitar problemas desnecessários naquele universo ainda desconhecido. Um interessante documento para consulta é o Código de Ética Mundial para o Turismo - Por um Turismo responsável, editado pela Organização Mundial do Turismo (OMT) ${ }^{4}$.

${ }^{4}$ http://www.turismo.gov.br/sites/default/turismo/o ministerio/publicacoes/downloads publicacoes/PREV IEW MTUR Codigo de Etica_Turismo_120_210mm_Portugues.pdf. Acesso em: 21 de dezembro de 2019. 
Diário de Viagens: compartilhando aventuras pelo registro da memória

Revista Ensaios, vol. 15, jul-dez de 2019.

\section{4) Sentimentos externados em texto:}

Essas informações são valiosas para o seu Diário de Viagens, mas nunca se esqueça de externar os seus sentimentos, dos tristes aos alegres. Revele o que está passando, seja a lembrança de uma música, de uma pessoa que retrata aquele momento, seja o encontro com algo que procura ou deixou para trás, como no filme Hanami Cerejeiras em flor (2008), da diretora Doris Dörrie. Nele, o protagonista (recém-viúvo) viaja ao Japão com o objetivo de realizar o sonho da esposa.

Descreva uma imagem, uma conversa ocasional, um encontro, uma piada, os bares, o gosto e o cheiro das comidas, o sabor e o resultado de uma bebida, a beleza da fauna e da flora. Detalhe as roupas, os rostos, ou mais, o clima. Retrate um momento de euforia ou uma situação inusitada. Contextualize e enriqueça a sua história com personagens e fatos. Componho o texto do seu jeito, como uma crônica da própria vida.

Apresente-se por meio de suas lembranças, como um flashback. Na prática, observe a sequência das imagens (fotos e vídeos) e também áudios disponíveis em sua câmera para escrever o seu texto. Se desejar, ilustre o seu texto inserindo o material em audiovisual, inclusive desenhos e ilustrações. Não esqueça de introduzir as legendas (uma para cada imagem ou áudio) ou texto-legenda (no caso de uma sequência).

\section{5) Considerações Finais:}

Boa parte dos blogs existentes trabalha a partir da experiência de viajantes, que acabam se tornando viajantes profissionais e que necessariamente não são nem jornalistas nem turismológos, mas pessoas comuns que compartilham suas experiências e dicas para facilitar a viagem de outros. Talvez seja possível compreender esse movimento em diferentes categorias: as pessoas que viajam e querem compartilhar a experiência de modo informal; aqueles que viraram viajantes profissionais e fazem compilação de dicas e sugestões de roteiros a partir de sua própria experiência e viajantes que contribuem com suas avaliações sobre destinos, 
Diário de Viagens: compartilhando aventuras pelo registro da memória

Revista Ensaios, vol. 15, jul-dez de 2019.

equipamentos, serviços em plataformas de reservas. Entende-se como um movimento muito significativo em que os turistas encontram espaço para compartilhar suas experiências e suas avaliações sobre elas.

Uma outra reflexão gira em tordo da literatura de viagem, com alguns poucos autores no mundo conhecidos e respeitados, que transformam suas viagens em leitura interessante e enriquecedora, que contribuem para formação da imagem de determinados destinos. Porém, parece que esse gênero não exerce mais tanta força, diante da imensa quantidade de textos curtos e diretos disponíveis em blogs e outros espaços digitais. Em tempos de leitura dinâmica, nada melhor que conduzir o texto como crônica - definida pelo jornalista, pesquisador e professor José Marques de Melo como "relato poético do real” (1985, p.120). Assim, a imaginação do autor torna-se um recurso a mais na construção da narrativa do Diário de Viagens.

Os famosos guias de viagem como Michelan e Lonely Planet perderam espaço ao longo dos últimos anos para o universo digital, com informações atualizadas e online. E também porque existe uma nova geração de turistas, conhecida como os Milleniuns $^{5}$, com outra lógica de busca e consumo de informação de viagem, que já nasceram no universo digital.

Por isso, o público e os especialistas têm ouvido relatos do sucesso sobretudo de blogueiros. Porém, essa interferência da escrita nas viagens é antiga. O gênero literário que capta com sensibilidade o que se passa no mundo sempre construiu imaginários sobre os lugares por meio de suas narrativas, como relatou a professora e pesquisadora Cremilda Celeste de Araújo Medina, autora do livro Ato presencial - mistério e transformação (2016), em entrevista concedida a Jorge Kanehide Ijuim e que foi transmitida pela Rádio USP, nos dias 8 e 15 de janeiro de 2017. ${ }^{6}$

\footnotetext{
${ }^{5}$ https://conceitos.com/geracao-y/ Acesso em: 20 de dezembro de 2019.

${ }^{6}$ Arquivos disponíveis pelo Repositório de Radiojornalismo da ECA-

USP:http://www.usp.br/cje/radiojornalismo/antigo/index3.php?buscar=Cremilda+Medina\&button=Busca r. Acesso em: 22 de dezembro de 2019.
} 
Diário de Viagens: compartilhando aventuras pelo registro da memória Revista Ensaios, vol. 15, jul-dez de 2019.

Desde o final dos anos 1800, os circuitos culturais clássicos - antiguidade romana e grega - os nobres que praticavam o Grand Tour já viajavam acompanhados de seus tutores para estudar in loco aquilo que haviam lido nos textos clássicos. Na obra O Corcunda de Notre-Dame, de Victor Hugo, publicada em 1831, a cidade é o grande personagem, os edifícios, o entorno adquire significado e torna-se atrativo, projetando Paris para fora dos limites nacionais.

A chamada leitura de viagem pode ser considerada difusora do patrimônio, valorizadora dos suportes e referências culturais como atrativos turísticos, a exemplo de muitos romances, expedições científicas e mesmo dos primeiros guias de turismo.

Atualmente, os interesses comerciais sobre os fluxos turísticos dominam a cena. Há blogueiros que escrevem sobre viagens que são convidados por gestores, ministros, profissionais de marketing turístico para viajarem para seus destinos, de modo a tornarem-se difusores, propagadores, promotores de viagens, lugares, destinos. Ou seja, essa influência é grande. Citamos os blogs, porque é o meio mais simples de divulgar o seu texto, mas existem outros, principalmente pelas redes sociais. E, caso não queira publicar, apenas brinque de escritor. Porém, caso deseje ir além e entrar no mercado editorial, siga os ensinamentos do professor e pesquisador Edvaldo Pereira Lima no livro Páginas Ampliadas: o livro-reportagem como extensão do jornalismo e da literatura (2009).

Lembre-se: quando for elaborar o seu texto, seja sincero e fuja das notícias prontas. Se achou um lugar legal, diga como foi a experiência. Porém, se a viagem foi cansativa, explique o motivo. Um outro fator relevante é detalhar a rotina. Nem sempre fique preso apenas aos lugares turísticos. Fale sobre o acaso, como uma loja onde encontrou as coisas que precisava e por um preço baratinho; ou um lugar onde foi possível descansar ou mesmo descreva os problemas que lhe incomodaram, como a sujeira, a fome etc. Sinta-se no direito de opinar, com o intuito de melhorar aquele lugar ou mesmo de trazer exemplos positivos para sua cidade e seu país. Procure transformar a sua vida e a vida dos outros, mostrando que a aquela viagem foi mais 
Diário de Viagens: compartilhando aventuras pelo registro da memória

Revista Ensaios, vol. 15, jul-dez de 2019.

além e acabou modificando a sua forma de agir e que, ao mesmo tempo, foi a sua gotinha d'água para mudar o mundo.

Escreva sobre as coisas boas e também as ruins de um local como uma proposta de debate. Quando retornar à sua casa, avalie se a viagem valeu a pena. Seja sincero e, se desejar, dê uma nota. Revele o que faria de diferente. Valorize alguns pontos, como o fato de não sofrer nenhuma doença grave ou mesmo se conheceu os lugares que havia marcado em seu roteiro. Traga o contraste com as outras culturas. Além de ser uma guia para os viajantes, pense que muitas pessoas não terão a mesma oportunidade de vivenciar a sua aventura e, por isso, o seu texto valerá também como uma experiência literária. 
Diário de Viagens: compartilhando aventuras pelo registro da memória

Revista Ensaios, vol. 15, jul-dez de 2019.

\section{Referências bibliográficas:}

GOETHE, J. W. Viagem à Itália 1786-1788. São Paulo: Companhia das Letras, 1999.

Hanami - Cerejeiras em flor. Direção: Doris Dörrie. Alemanha/França, 2008. Duração: 127 minutos. Bavaria Filmes.

HUGO, V. (1802-1885). O Corcunda de Notre-Dame (1831). São Paulo: Scipione, 2011.

LIMA, E. P. Páginas Ampliadas: o livro-reportagem como extensão do jornalismo e da literatura. Barueri: Manoel, 2009.

MEDINA, C. C. A. Ato presencial - mistério e transformação. São Paulo: Casa da Serra, 2016.

MELO, J. M. A opinião no jornalismo brasileiro. Petrópolis: Vozes, 1985.

ORGANIZAÇÃO MUNDIAL DO TURISMO (OMT) Código de Ética Mundial para o Turismo - Por um Turismo responsável. Disponível em:

http://www.turismo.gov.br/sites/default/turismo/o_ministerio/publicacoes/downloads_p ublicacoes/PREVIEW_MTUR_Codigo_de_Etica_Turismo_120_210mm_Portugues.pdf Acesso em 21 de dezembro de 2019

REPOSITÓRIO DE RADIOJORNALIMO DA ECA-USP. Disponível em: http://www.usp.br/cje/radiojornalismo. Acesso em: 22 de dezembro de 2019. 